\title{
Sustainable Design of Waste Fabric and Contemporary Textile Materials
}

\author{
Fang WANG \\ College of Fashion and Design, Donghua University,1882, Yan An Road(w),200051,Shanghai,China \\ ypnypj@126.com
}

\begin{abstract}
Through sorting and researching the visual characteristic, design characteristic and culture characteristic of waste fabric, combining with the analysis of designers and brand product cases, this article puts forward the material attribute for sustainable use of waste fabric and its creative possibilities in textile design, and seeks an updating path for the sustainable development of contemporary textile design and material update.
\end{abstract}

Keywords-Sustainable material; waste fabric; usefulness and uselessness; cultural inheritance and fashion trend.

\section{I.INTRODUCTION}

Today, with the increasingly significant role and importance of materials in design, the interactive relation between originality and materials has become closer and closer. The development of human science \& technology promotes the technology and intelligence of materials. For instance, the innovative textile material of nano-fibers has gradually entered our life, bringing us unprecedented convenience and consumption experience.

Meanwhile, with overflowing materialization and inflated consumption, under the accelerated development of each product production chain, energy crisis and public nuisance have also become matters with increasingly urgent consciousness of people. The waste fabric in the rapidly developing textile and garment industry has become a great cost paid for development.

Since the middle and later period of the 20th century, "environmental protection" and "green" have gradually drawn people's attention and permeated various fields. The Rio Declaration of 1992 determines a series of principles, systems and measures regarding international environmental protection, and reflects the world's common aspiration for jointly protecting the human environment, thereby, becoming a milestone in the international environmental protection history. In the 21st century, "low carbon" and "sustainable development" are the core words of art design, and is the common view of designers in the world.

The focus on and efforts in sustainable materials have become the trend and representation of product design in European and American countries. Relevant organizations emerged at the moment so as to devote themselves to the expression and delivery of sustainable, recyclable, green and low-carbon design. This is evident in the creative works of students at the worldwide famous design colleges \& universities and in young designers' works. It has become not only a design attitude of young designers, but also their responsibility for humans and the society.

\section{II.SUSTAINABLE CHARACTERISTIC OF WASTE FABRIC}

Waste fabric mainly includes the redundant textile materials in the manufacturing and processing of textile and garment products, as well as the clothes and domestic fabric abandoned by people. The waste fabric in manufacturing and processing comprises defective fabric and tailoring oddments, also known as leftover material. The increment of waste fabric is directly proportional to the development of the textile and garment industry, and its negativity has formed a heavy social burden.

Moreover, waste fabric has a reversible attribute. In other words, it can "resurrect", becoming the sustainable attribute of the material.

Sustainable material refers to the material with a full consideration of ecological sustainability in resources and environments in the whole design, production and usage period, as well as the characteristics of recycling, reuse, circulating, pollution reduction and energy consumption reduction, namely, the " $3 \mathrm{R}$ - Reduce, Reuse and Recycle" attribute in green design. In the entire life cycle of design, production and use, the products produced by the utilization of waste fabric not only realizes the functionality of redesign and the service life attribute, but also meets the environmental goals and requirements to the maximum extent. In the concept, waste fabric obtains the significance of sustainability, which is related to the process characteristic in visual characteristics of waste fabric, and manifests the culture and spirit attributes of material.

Sustainable material corresponds to sustainable design. The visual characteristic is one of the important elements of design. As with other designs, as a material for generating the product, fabric is an important element for the brand positioning of textile products. Its material attribute determines the style and consumption orientation of a product.

Textile and garment design is always closely related to fashion, and is accompanied by the development of the human culture and the art history, thereby, becoming a sign of each era. With high information and high digitization now, while "vector graphics", "digital process" and high-tech materials become a style of textile and garment fashion culture, such words as "retro", "reminiscence", "tradition" and "emotion" also become another background culture of the fashion trend, which is used to drive the nature, individuation and antipopularization of products, as well as relevant "handicrafts" and "antiquating process" to become a fashion and a fashion wind vane. Its deeper design spirit is the sustainability of accumulation, sedimentation, inheritance, history temperature and cultural memories. 
Meanwhile, a new meaning is also injected in the concept of the popular "luxuries". It may be annotated as follows: today, we overuse cheap and short-lived consumer products (disposable wipes, tablecloth, socks, underwear, etc.); the production and use of cheap products is undoubtedly a consumption model of making rubbish; however, the product design advocated in "luxuries" is high-quality material, fine workmanship, as well as historical carrying and cultural endowment. Through commodities, the cherishing for and durability of objects are passed on to allow the objects to obtain sustained use. From advocating objects and cherishing objects to treasuring objects, valuables contain preciousness and nobility. The above are the multidimensional manifestations of sustainability.

With a focus on the concept of "quality material" used in luxuries, the saying of Ma Ke, founder of China's famous women's clothing brand "Wu Yong" (uselessness), is cited in this article, "Clothing is the layer which is the closest to skin. Its value lies in the transmission and expression of emotions. In this sense, the so-called fashion and vogue are both unimportant.” "I'm willing to pursue the most luxurious and richest spiritual world in the initiative selection of creating the most essential and simplest life." The brand named "Wu Yong" coincides with the "useless design". Its spirit lies in fewer resources, more creativities, and contains the Taoist philosophy spirit of cherishing and advocating objects and seeking natural inaction.

The designer Ma Ke once had a strong aversion to the machine-made garment assembly line. "Uselessness" advocates using a design method of disintegrating materials to reshape materials. The material and product attitude of shaping "luxury" with "poverty" is an annotation to sustainable textile design materials.

\section{III.REALIZABLE CHARACTERISTIC OF WASTE FABRIC}

Waste fabric often has the following features in such patterns as texture and color due to use or other reasons: abrasion, defect, deformation, wrinkle, fading, chromatic aberration, dimness, etc. Besides, it has certain limitations in area and shapes. Some waste fabrics from specific regions and year possess precious signs of the times patterns and technologies. With the loss of time, the graphics, color and hand feeling of fabric are all branded with time traces. As the saying goes, "No leaves are exactly the same in the world." Sometimes, fabric is also very precious. Therefore, each piece of waste fabric is unique, which is one of its values.

In Zhuangzi: the Human World, Zhuangzi wrote, "Cinnamon bark can be eaten; therefore the tree is cut down. Lacquer can be used; therefore the tree is scraped. All men know the utility of useful things; but they do not know the utility of futility." Guo Xiang, metaphysician of the Western Jin Dynasty gave such an annotation to Zhuangzi, "Usefulness is the instrumental value of others, while uselessness is its own target value." It further expounds the meaning.

The "uselessness", namely, the waste and oldness of waste fabric, is converted into "usefulness" through the concept of design, and sustainability is given to the material. While being given a new start, it also spawns value and significance.

The product designed and manufactured by the utilization of waste fabric is also an important traditional manifestation, such as the patchwork quilts of North America and the monk's ragged robe of China. There are also clothes made down. With the worn-out removed, adults' clothes can be changed into children's clothes. In addition, old woven carpets can be transformed into small objects like back cushions and seat cushions. Before the 1980s in China, it was a very common phenomenon that housewives mended and altered the clothes of their family members. With the growing up of children, children's sleeves or trouser legs might be spliced so as to meet the need for the change in length. Ingenious housewives might skillfully utilize the change in colors and patterns to change the spliced part into edging. The form of two old garments synthesized into a "new" garment is a common processing mode. In that period, all women could knit sweaters. In the unpicking and washing process, the knitted sweater material could be transformed time after time in finished products. In the re-knitting process, as the worn-out part of single-colored woolen yarn is removed, a new colored woolen yarn might be added, spliced or synthesized into a strand with the original woolen yarn. Thus, clothes could become multi-colored. Needles and threads carry the family affection contained in needlework, and are the memories and spiritual wealth left to us by those years.

For the reuse of waste fabric, there are a number of designers and brand products committed to it. And remarkable achievements have been made.

Zhang $\mathrm{Na}$, founder and independent designer of FAKE NATOO in Shanghai, owns an independent project - Reclothing Bank, which is aimed at recycling, cleaning up and arranging old garments, and classifying and reorganizing them according to the types of fabric so as to complete the redesign of garment accessories.

As the poster of the brand salon activity reads, "Clothes not only bring us beauty and happiness, but also links our past and future with the present. Old clothes, unpicking and washing, regeneration... When we wear remade clothes, memories and emotions continue to accompany us. Due to special significance, the clothes undergoing numerous years cannot be abandoned at will. Accompanied by clothes, the past experience is circulated in a new form. Let's take a new look at these old clothes from the perspective of redesign, and use the existing material to prolong the service life of clothes with the design power." The garment accessories of Reclothing Bank give products extraordinary significance and connotations due to the material attribute thereof.

Martin Margiela, a Belgian designer who are famous for the technology of deconstructing and reorganizing clothes, and Maison Martin Margiela founded by him created various fashion works made of waste fabric, attracting worldwide attention. In the period, there are a number of design works with old gloves, old socks, Indian hand-dyed fabric, silk rugs, machine embroidery logos, cloth strips, ropes and the like as materials. In Martin Margiela's works world, waste fabric can always be integrated and mutually generated with various modern materials such as coatings, PVC, meshes, beads and 
diamonds. That's impressive. The "antiquating process" of fabric, the display of old hangers and old mannequins, the dim and mottled environment... The "outdated" style of the products of Maison Martin Margiela brings an emotional sense of belonging, passing on the concept of sustainable fabric to people in the world. It is no wonder that Martin Margiela said, "Old clothes are better."

Alison Chernick, American writer and director, filmed a documentary - "The Artist is Absent" to record the originality behind the most famous exquisite works of Martin Margiela in the recent two decades, and to reveal the subversive profound influence of this designer who is hailed as a genius in the fashion field. In 2015, this film was successfully nominated for Best Documentary Short Subject at the Tribeca Film Festival, New York.

In Singapore, young sister designers Enqi and Xin founded the brand "Maki Squarepatch". Maki is the name of a dying stray cat saved by the sisters' mother. The brand is committed to creating cloth artworks originated from waste fabric. Their products include garment accessories, back cushions, home accessories and toys. Thus, every hand-sewn work is unique. With original features, waste fabric adds warmth and memories of years behind the modeling full of fun.

\section{IV.CONCLUSION}

The product made of the waste fabric in sustainable materials is like a circular trace where the human design changes from a luxurious terminal point to an unadorned starting point. The terminal point is also the starting point, but their properties are totally different. In the period, it is mingled with the rational art creation activity conducted by people under the thinking of the life meaning. As the saying goes, "All things alike go through their processes of activity, and then we see them return to their original state. When things in the vegetable world have displayed their luxuriant growth, we see each of them return to its root. This returning to their root is what we call the state of stillness; and that stillness may be called a reporting that they have fulfilled their appointed end. The report of that fulfillment is the regular, unchanging rule. To know that unchanging rule is to be intelligent." (See Tao Te Ching by Laozi) It coincides with Laozi's philosophical spirit of "unity of heaven and man".

Today, the society is suffused by material consumption, culture consumption, mass culture and consumer culture, which have certain acceptance limitations on the products made of waste fabric. It is limited by the product characteristics. However, the sustainability, significance and value of the design driven by it become increasingly clear and obvious.

\section{REFERENCES}

[1] Zhang Li, Salon Themed on "Sustainability of Materials", Urbanism and Architecture, May 2012

[2] Yu Qinghua, Philosophical Analysis of “Useless Design”, Journal of Nanjing Arts Institute, March 2010

[3] Chen Junda, Useless Design, Beijing, Posts and Telecom Press, 2011

[4] Maison Martin Margiela website http://www.maisonmartinmargiela.com/

[5] Wuyong website http://www.wuyonguseless.com/Default.aspx

[6] Reclothing Bank - Xinhuanet, http://news.xinhuanet.com/fashion/2013-12/11/c_125839598.htm 